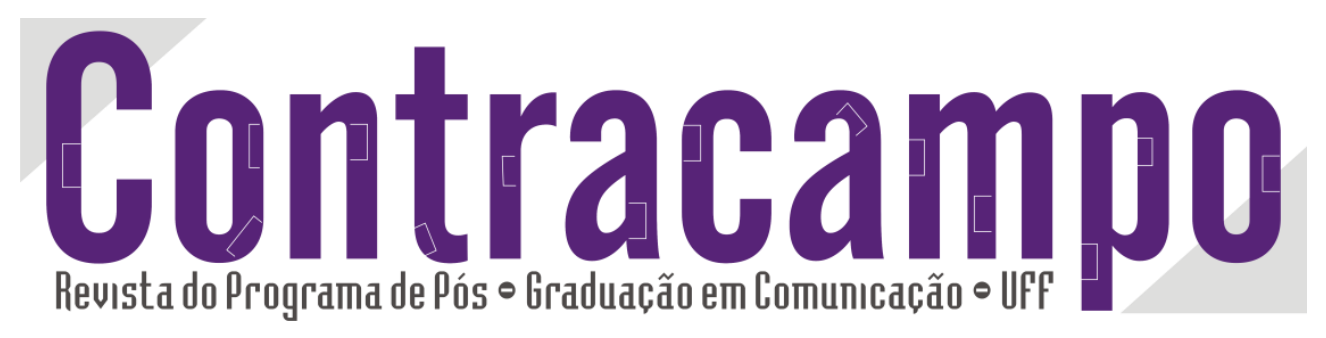

\title{
A experiência comunitária e a morte do sujeito
}

\section{The community experience and the death of the subject}

\section{Eduardo Yuji Yamamoto \\ vudieduardo@bol.com.br}

Doutorando em Comunicação pela Universidade Federal do Rio de Janeiro (UFRJ). Jornalista e especialista em Comunicação

Comunitária pela Universidade Estadual de Londrina (UEL). Mestre em Comunicação Midiática pela Universidade Estadual Paulista (UNESP).

Agradecimento especial a Cezar Migliorin pela relatoria da versão inicial deste artigo apresentado na XX COMPÓS, Porto Alegre, 2011. Agradeço também aos demais participantes do GT Comunicação e Experiência Estética pelas sugestões.

\section{PPGCOM UFF}

Ao citar este artigo, utilize a seguinte referência bibliográfica

YAMAMOTO, Eduardo Yudi. A experiência comunitária e a morte do sujeito. In: Revista Contracampo, v. 24, n. 1, ed. julho, ano 2012. Niterói: Contracampo, 2012. Pags: 86-104.

Enviado em: 12 de jan. de 2012

Aceito em: 18 de jun. De 2012

\section{Edição 24//2012}

Ensaio temático "Sociabilidades em rede"

Contracampo

e-ISSN 2238-2577

Niterói (RJ), v. 24, n. 1, jul./2012.

www. uff.br/contracampo

A Revista Contracampo é uma revista eletrônica do Programa de PósGraduação em Comunicação da Universidade Federal Fluminense e tem como objetivo contribuir para a reflexão crítica em torno do campo midiático, atuando como espaço de circulação da pesquisa e do pensamento acadêmico. 


\section{Resumo}

O uso do conceito sociológico de comunidade nas pesquisas comunicacionais brasileiras (sobretudo na comunicação comunitária e na cibercultura), embora ilumine algumas questões da atualidade implica na exclusão de dois objetos importantes, quais sejam, as manifestações singulares e a vinculação humana. Autores como Bataille, Nancy, Blanchot, Agamben e Espósito, ao proporem uma nova leitura do conceito de comunidade, permitem restituir tais objetos à Comunicação. A contribuição destes autores será analisada aqui a partir de uma dupla perspectiva: 1) crítica do conceito tradicional de comunidade $\mathrm{e}$ abertura às singularidades múltiplas; 2) apresentação da comunidade enquanto fenômeno impessoal, sensível e relacional. Comunidade, segundo tais autores, recupera a complexidade da vinculação humana a partir de um paradoxal jogo que põe fim ao sujeito (entendido como instância de controle do processo de subjetivação) ao mesmo tempo em que se constitui como fonte de produção do novo. Palavras-chave: Communitas, Vinculação, Dessubjetivação.

\section{Abstract}

Although the sociological concept of community in the Brazilian Communication Research (especially in Community Communication and (yberculture), enlightens current issues, it implies the exclusion of two important objects: the singular manifestations and human bonding. Authors such as Bataille, Nancy, Blanchot, Agamben and Esposito, by proposing a new reading of the concept of community, restore those objects to Communication. The contribution of these authors will be reviewed here from a dual perspective: 1 ) critique of the traditional concept of community and openness to multiple singularities, 2) presentation of the community as an impersonal, sensitive and relational phenomenon. Community, according to these authors, retrieves the complexity of human bonding by putting an end to the subject (understood as a control instance of the process of subjectivation) while it is as a source of producing something new.

Keywords: Communitas, Human Bonding, Desubjectivation . 
A sociedade não se construiu sobre a ruína de uma comunidade... a comunidade, longe de ser o que a sociedade teria rompido ou perdido, é o que nos acontece - questão, espera, acontecimento, imperativo - a partir da sociedade... Nada foi perdido, e por esta razão nada está perdido. Só nós estamos perdidos, nós sobre quem o "laço social" (as relações, a comunicação), nossa invenção, recai pesadamente...

(Jean-Luc Nancy, 1986. La communauté désoeuvrée)

$\mathrm{N}$ uma revisão teórica da sociologia do século XIX, Robert Nisbet observou que nenhuma outra imagem (ou representação) sociológica teve mais poder de legitimação de uma busca que o "simbolismo da comunidade". Para ele, a "redescoberta da comunidade" no referido período, auge da expansão capitalista industrial, instalou entre os sociólogos conservadores contrários ao discurso da modernidade o desejo de restauração de "algo" que ficou perdido em meio a este processo, sendo responsável por conflitos nos mais diferentes domínios para a apropriação do comum. "A redescoberta da comunidade tradicional e de suas virtudes constitui um dos pontos centrais dos trabalhos de todos os conservadores" (Nisbet, 1993: 74).

A leitura de Nisbet ${ }^{1}$ permite-nos inferir a comunidade como artifício político capaz de fundamentar práticas de controle e intervenção social. Assim, independentemente de quem fala da comunidade (ou em nome da comunidade), o fato é que o termo se tornou uma palavra mágica, legitimadora de todo o empreendimento político moderno, desde as formas benevolentes e salvacionistas (ou neocolonialistas) às manifestações comunistas e nazifascistas que o século XX muito bem conheceu. Para se ter uma ideia do poder legitimador da teoria (tanto quanto do conceito) como fundamento da prática intervencionista, basta retomar o polêmico trabalho de Rodolfo Stavenhagen, "Sete teses equivocadas sobre a América Latina". Segundo Marcos Palácios (1990), o referido artigo se tornou polêmico justamente porque Stavenhagen contestou o quadro teórico que fundamentava grande parte das práticas de grupos e partidos políticos que assumiram para si a tarefa de transformar (radical ou gradualmente) a realidade da América Latina. Para Stavenhagen (Apud Palácios, 1990:

\footnotetext{
${ }^{1}$ Para Nisbet, pouco tempo depois, a mesma reivindicação será retomada pelos progressistas. Esta disputa pela comunidade, que coloca em jogo sujeitos que "falam em nome da comunidade" é objeto do texto "O discurso comunitário" (Yamamoto, 2008).
} 
104), muitos destes conceitos e teorias foram aceitos como verdades absolutas por intelectuais, políticos, estudantes, pesquisadores e professores latino-americanos. Nem os fatos, nem as pesquisas recentes que rechaçaram tais premissas foram capazes de enfraquecê-las.

Não pretendemos polemizar, tampouco rechaçar qualquer tese, mas a retomada do texto de Stavenhagen por Palácios nos pareceu oportuna para iluminar algumas questões e observar que algo semelhante tem acontecido no campo comunicacional, sobretudo em setores da comunicação comunitária e da cibercultura, no que diz respeito à expropriação do comum. No primeiro, é recorrente não só pesquisas que denunciam a ingerência (política e religiosa) ou a opressão local sobre veículos comunitários de comunicação e grupos marginalizados da sociedade, como também aquelas que chamam a atenção para o potencial emancipatório ou desalienante destes mesmos grupos. Não obstante, tanto num caso quanto noutro, fala-se de um comum que homogeneíza indivíduos e exclui (ou estigmatiza) tantos outros para dar cabo ao seu objetivo político ${ }^{2}$. Nas redes telemáticas, a mesma prática pode ser verificada nas chamadas comunidades virtuais: em todas elas se faz presente um conjunto de usuários e um administrador (o dono ou criador da comunidade) que gerencia o comum, cuida para que este não transponha os seus limites ${ }^{3}$.

Objeto de grande valor e, por isso, de disputa ora pelas forças políticas, ora pelo Capital, pode-se constatar que, durante toda a história, a política ocidental gravitou, predominantemente, em torno da luta pela comunidade, pela apropriação (ou suposta defesa) de uma substância comum. O efeito disso na Comunicação repercute na ênfase dada às pesquisas sobre as disputas políticas em detrimento da comunicação stricto senso (processo de vinculação, produção de vínculos) ${ }^{4}$, objeto de pouco interesse para

\footnotetext{
${ }^{2}$ Há casos em que o direcionamento político é ainda mais explícito (como, por exemplo, na pesquisa-ação ou pesquisa participante), transparecendo um imperativo (um “dever-ser") do pesquisador sobre a comunidade.

${ }^{3}$ Além disso, segundo Henrique Antoun \& Fábio Malini (2010), pode-se observar na web 2.0 uma prática expropriativa do comum voltada à tributação para o uso de bens comuns como o conhecimento e outras produções culturais, sob pena dos copyrights. As redes sociais, na verdade, compõem estes conjuntos de pessoas que compartilham mais do que "mundos comuns" ou ideologias, mas "informações seguras" ou senhas de acesso a bens exclusivos tendo sempre alguém interessado em lutar por elas.

${ }^{4}$ Comunicação, comunidade e comunhão possuem um mesmo radical, munus, que em latim designa onus, officium e donus (obrigação, dever, dom, dádiva). Trata-se de um traço impessoal que atravessa o sujeito, o arranca de si e o liga ao Outro. O estudo da vinculação humana (comunicação stricto sensu) constitui um estudo de comunidade como relação, isto é, de um munus comum e originário. Retornaremos a isso mais adiante.
} 
as forças produtivas conformadoras da epistème do campo. De fato, em muitas pesquisas, a comunicação assume papel coadjuvante sendo considerada apenas instrumento (ou técnica) a serviço da política. Não deslegitimamos estas questões, nem descartamos o alcance e sua importância - aliás fundamental para a constituição do campo como nos lembra Muniz Sodré ${ }^{5}$-, mas nos parece igualmente importante apresentar fenômenos de ordem comunicacional que estas formas totalizadoras (midiatizadoras) não nos permitem ver, a exemplo da constituição de laços comunitários e dos processos de vinculação.

Desde os anos 80 do século passado, pensadores como Nancy e tantos outros (Maurice Blanchot, Giorgio Agamben, Roberto Espósito) têm insistido na necessidade de se pensar nas expressões políticas que transpõem as fronteiras dos aparatos políticos representacionais (conceitos). Por isso, sugerem um olhar atento não apenas para as formas de resistência provindas das multiplicidades e "singularidades sociais", como também a dessubstancialização da própria comunidade como mecanismo capaz de retirar os sedimentos políticos depositados durante anos pelos teóricos e, assim, deixar livre a comunidade, permitir que a comunidade seja tal qual é$^{6}$. Essa necessidade não é meramente exercício especulativo, mas possibilidade de avançar as nossas pesquisas comunicacionais para além da centralidade técnica, de fazer emergir questões transversais como as múltiplas formas de vida, vinculação e resistências (sejam elas dentro ou fora da mediatização) ou a experiência estética comunitária como experiência radical da diferenciação e aproximação de seres humanos. Tais objetos são negados pelo conceito sociológico de comunidade que totaliza os fenômenos numa substância comum (língua, identidade, etnia, etc.) e define, de saída, o espectro comunitário pelo alcance

\footnotetext{
${ }^{5}$ Uma excelente crítica sobre a influência da política na determinação epistemológica pode ser conferida no texto "Sobre a epistème comunicacional". Para Sodré (2007), o vínculo aparece como importante objeto da comunicação, todavia sem tanto interesse para as forças que conformam o campo epistemológico, de modo que a condição lógica e cognitiva que o faz emergir no interior da técnica não parece tão decisiva quanto as influências do político e do econômico na delimitação de objetos comunicacionais.

${ }^{6}$ Martin Heidegger propõe um "estudo" da comunidade a partir de uma "lógica do abandono". "[...] a comunidade abandonada à sua simples vida-em-comum, privada já da sua essência, é a única comunidade possível, a comunidade que se torna toda comum, sem barreiras identificáveis, raciais ou de outro tipo, que correspondem, ao contrário, à lógica da idéia, do discurso da idéia, ou à ideo-logia" (Tarizzo, 2007: $34-35)$.
} 
espacial do meio técnico ${ }^{7}$ (e não da força intrínseca do vínculo), conduzindo, muitas vezes, a uma abordagem tecnicista.

\section{Imanência da comunidade}

O tradicional conceito de comunidade, assim como muitos outros conceitos modernos, encontra-se ancorado na metafísica ocidental substancialista e transcendente. Nesta tradição, de Platão a Descartes, a substância garante o princípio de realidade da comunidade no mundo, assegurando estabilidade ontológica, ao passo que sua transcendência a enclausura numa utopia. Daí porque comunidade se tornou alvo de forças políticas e sociais (conservadoras e revolucionárias) sendo vulgarizada com a imagem de paraíso perdido para ser reconquistado no presente ou como modelo ideal de sociedade a ser construída para o futuro ${ }^{8}$.

Autores como Agamben (1993) e Nancy (1986), no entanto, propõem outra leitura da comunidade, entendendo-a como potência de realização. O poder desta comunidade "que vem" (como quer Agamben) ou deste fantasma (como fala Nancy) não se deve àquilo que ela carrega em si (um conteúdo lógico-racional, uma ideia revolucionária ou símbolos devastadores), mas a ameaça de algum dia vir a ser - medo do imprevisível, do devir louco que tudo desestabiliza e destrói. Para Agamben, o futuro da Política estaria neste horizonte desnivelado pela expectativa de algo (comunidade) que colocaria todas as representações políticas em crise: partidos, associações e agremiações culturais, dispositivos jurídicos etc. Georges Bataille (1992) chamou isso de "comunidade dos sem comunidades", uma associação constituída por seres excluídos de todas as formas de representação (política, social, cultural).

Seja uma comunidade "que vem" ou constituída por "aqueles que não têm comunidade", o fato é que estas formas sem substância constituem as únicas capazes não só de resistir a qualquer totalização como colocar em risco toda a Política ${ }^{9}$. Não obstante, definem a própria noção de comunidade, pois participa (mesmo que

\footnotetext{
7 No caso da comunicação comunitária, jornal, rádio e TV comunitárias (aura eletromagnética); na cibercultura, as redes sociais, as comunidades virtuais ou os chamados clusters (espectro técnico).

${ }^{8}$ Exemplo disso é a "sociedade perfeita" de Rousseau, segundo o qual possui aspecto comunitário.

${ }^{9}$ A abdicação de tudo, a recusa de "seus membros" de se entregam a qualquer formação ou representação política (um partido, uma ideologia) carrega a possibilidade de uma auto-extinção. Sobre isso é bastante esclarecedor a leitura que Blanchot (1983) faz de "Maio de 68".
} 
efemeramente) da constituição de todas as formações sociais baseadas numa substância comum (concepção tradicional de comunidade), porém nessas não se detêm, atuando, inclusive, como força gregária destrutiva, de desagregação destas mesmas formações.

Comunidade, neste caso, não se identifica com qualquer traçado cartográfico cujos rígidos contornos delimitam uma substância (comum) em seu interior, como sugerem "as figuras midiáticas, políticas, imperiais que pretendem hipostasiá-lo, representá-lo ou expropriá-lo", mas, como sugere Peter Pál Pelbart, uma "vitalidade social pré-individual”, "pura heterogeneidade não totalizável", enfim um reservatório de "singularidades em variação contínua" ou um ilimitado (apeíron) apto às individuações as mais diversas (Pelbart, 2003: 30). Enquanto tal, pode ser verificada naquelas manifestações de ocorrência única, no conjunto de formas expressivas que realizam ações sem assumirem autoria partidária a exemplo das mídias táticas ou de certos programas infames e nonsense. Eventos que surgem e, deste mesmo gesto, desaparecem.

A comunidade pensada enquanto forma ou simples potência (e não como substância já efetivada) implica numa "dessubstancialização da comunidade" que pode ser compreendida a partir de uma dupla perspectiva (teórica e metodológica):

a) deslocamento do conceito de comunidade, de uma ontologia estável, substancialista e transcendental para um plano de imanência e; consequentemente

b) apresentação de um objeto comunicacional (o vínculo) desdobrado da experiência da dessubtancialização ou dessubjetivação do ser (experiência comunitária) ${ }^{10}$.

Detalhemos estas duas perspectivas:

a) É justamente a substância comum e já efetivada que dá à comunidade, em sua acepção sociológica, um caráter litigioso. A compreensão da comunidade como um “nada-em-comum" (Nancy, 1986) ou forma sem substância, a nosso ver, destitui a comunidade de qualquer valor útil (seja para a política, seja para o mercado) transformando-se num desdobrar-se em si (e para si), um acontecer em seu desenrolar próprio. A comunidade, neste caso, deixa de ser algo ontologicamente estável, substancialista, e passa a co-existir (perigosamente) aos eventos; de categoria política,

\footnotetext{
${ }^{10}$ Nosso objetivo aqui é justamente captar o ser da comunidade nesta transição ontológica. Conforme assinala Espósito "[...] comunidade não é o entre do ser, mas o ser como entre" (Espósito, 2007: 19).
} 
portanto, ela passa a compor, em nosso esquema, uma categoria do "impolítico"11, o que a desvincularia de qualquer forma de apropriação política do comum, passando a ser aquilo que é (Ser-aí).

Para Nancy (1986), é o nada ou o vazio (e não qualquer substância), o que há de comum na comunidade. $\mathrm{O}$ fato de todos possuirmos um vazio comum e originário é o que nos movimenta, nos impele à relação ou à vinculação, permite-nos a consciência de si. Não somos seres, afirma Nancy, mas "seres-com" (a partícula "-com" é aquilo que desestabiliza o ser). Isso porque não somos isolados, mas sempre em relação. Comunidade, para ele, é a reunião destes "seres-com", seres esvaziados. Trata-se de um espectro ou "fantasma" que nos informa que algo nos falta, que não somos seres completos e auto-suficientes ou que o ser, para sê-lo, deve, necessariamente, ser "com”. O “-com", sendo algo intrínseco ao "ser", possui natureza impessoal, traço que atravessa os sujeitos e, de certa forma, os mata enquanto sujeito (aqui entendido como entidade isolada e autossuficiente), fantasma que circula, força dissociativa impiedosa que arranca o sujeito de si levando-o para "fora de si”, para a absoluta relação. É exatamente isso que faz a dessubstancialização (e não a substância) o comum de toda a comunidade - por isso, diz Nancy, a comunidade é um vazio ou um "nada-em-comum".

Como pensar a comunidade como algo dessubstancializado? Como, então, "estudar" a comunidade se nos falta a substância de apoio? Nancy responde: como experiência. Ora, se acompanharmos o seu desenvolvimento reflexivo chegamos à conclusão de que, enquanto espectro, forma ou potência, a comunidade não pode ser captada, analisada, decomposta, enfim estudada, senão como experiência. Não qualquer experiência, diz Nancy (respaldado em Bataille), mas experiência da morte. Esta, assegura Bataille, "coincide em tudo e por tudo com a experiência da comunidade" (Apud. Tarizzo, 2007: 48).

[...] a experiência da morte é a experiência da desapropriação de nós mesmos. A morte não é jamais minha: é o faltar do que possuo. Ninguém pode viver a própria morte, a morte é sempre do outro. Mas nem mesmo o outro possui e vive a sua morte. A morte é em essência uma impropriedade que nos nivela a todos. E este é o segredo da comunidade: a partilha da impossibilidade de morrer a própria morte.

\footnotetext{
${ }^{11}$ Impolítico, segundo Espósito, como aquilo que foge às representações políticas, ou seja, aquilo que está além ou aquém dos limites do conceito, a exemplo das singularidades. Não se trata- de um "a-político" ou um "des-político", pois estes ainda estariam dentro "do político", como negação.
} 
A experiência da morte - entendida como abandono de cada uma identidade não a uma identidade comum, mas a uma comum ausência de identidade - equivale portanto, à experiência de uma comunidade: já que a morte é a nossa comum impossibilidade de ser aquilo que nos esforçamos para a continuar a ser: indivíduos isolados. (Apud. Tarizzo, 2007: 48)

b) Comunidade, neste sentido, constitui uma espécie de centro expropriador das substâncias individuais, uma espécie de buraco negro para onde as subjetividades são atraídas e se dissipam num comum. Esta, enquanto potência, como frisamos, pode apenas ser sentida como "experiência interior" que, conforme Bataille, não se refere à consciência de si (diálogo de mim comigo mesmo), mas sentimento de si cada vez mais ausente. Ela acontece, diz Bataille, como um êxtase (ex-stase) em sentido literal: um sair de si. Tal como a morte, a experiência interior de Bataille descreve a experimentação de um eu cada vez mais ausente, que experimenta o esvaziamento de sua interioridade (subjetividade) a partir de um fora, um Outro que tem prioridade sobre ele; experiência que comparece ao ser "na crise que o põe à prova, é a atuação do ser numa passagem que vai da continuidade à descontinuidade, ou da descontinuidade à continuidade" (Bataille, 1992: 95).

Isso significa compreender a comunidade como a máxima externalidade (alteridade) do sujeito, não como projeção de interesses individuais num espaço (por exemplo, a Internet), tão comum às teorias sobre redes sociais e agrupamentos urbanos. Estas não passam de uma grande interioridade só que lançadas num lugar externo (realização narcísica). Diferentemente de uma projeção interesseira ou de um conjunto de individualidades conectadas por aparatos técnicos e jurídicos, aqui o indivíduo se vê extraviado; ele vê esvair-se sua subjetividade ou interioridade por um traço que o subtrai $^{12}$.

\section{Êxtase da comunidade}

A partir destes excertos podemos estabelecer as condições nas quais a comunidade aconteceria ou poderia ser experienciada. Seguindo uma abordagem

\footnotetext{
${ }^{12}$ Esta é também a concepção de comunidade segundo Espósito (2003). Para ele, este se constitui não como compartilhamento de uma propriedade ou substância comum, mas uma impropriedade, impossibilidade da posse. O munus (o dar obrigatório da economia da dádiva) é o que nos vincula e o que nos mantêm unidos, em relação, numa cadeia interminável de doação.
} 
estóica, bem delineada pelo filósofo Gilles Deleuze (2007), isso só poderia ocorrer num "plano de consistência" ou da "composição".

Num plano de composição, trata-se de acompanhar as conexões variáveis, as relações de velocidade e lentidão, a matéria anônima e impalpável dissolvendo formas e pessoas, estratos e sujeitos, liberando movimentos, extraindo partículas e afetos. É um plano de proliferação, de povoamento e de contágio. Num plano de composição o que está em jogo é a consistência com a qual ele reúne elementos heterogêneos, disparatados. (Pélbart, 2003: 30)

No êxtase, o "pesquisador" sentiria sua dissolução na comunidade até o seu completo esfacelamento, conduzido-se pela voz que o chama, exercendo sua condição de espírito livre ${ }^{13}$. Nesta duração estética, ele descreveria desde o primeiro chamado (afeto) que desencadeou o processo de esvaziamento ou assujeitação, à própria arquitetura desta atmosfera que se cria e produz o recolhimento no Outro, sendo justamente aí onde emerge sua própria consciência.

O ser procura não ser reconhecido, mas contestado: ele vai, para existir, em direção ao outro, que o contesta e, às vezes, o nega, a fim de que ele exista somente nessa privação, que o torna consciente (é a origem da sua consciência) da impossibilidade de ser ele mesmo, de insistir como ipse ou, se o queremos, como indivíduo separado [...] (Blanchot, 1983: 17).

Este Outro de que fala Blanchot, seguindo a filosofia ética de Emmanuel Lèvinas, constitui não só a alteridade simples (tu), mas sua versão absoluta (Outrem ou o terceiro Outro que está além de eu e tu). Por isso, não pode ser entendida simplesmente como um outro sujeito (tu).

O Outro metafísico é outro de uma alteridade que não é formal, de uma alteridade que não é um simples inverso da identidade, nem de uma alteridade feita de resistência ao Mesmo, mas de uma alteridade anterior a toda a iniciativa, a todo o imperialismo do Mesmo; outro de uma alteridade que não limita o Mesmo, porque nesse caso o Outro não seria rigorosamente Outro: pela comunidade da fronteira, seria, dentro do sistema, ainda o Mesmo. O absolutamente Outro é Outrem;

\footnotetext{
${ }^{13}$ Encontramos na escritora portuguesa Maria Gabriela Llansol vasta produção sobre a comunidade. Nos termos aqui pretendidos, é sugestivo o seguinte excerto: "Para dizer de uma maneira crua, só o escravo pergunta quem é; o homem livre segue quem o chama. Segue, mas não pertence à voz que o chama" (Llansol Apud Mendes, 1995: 2).
} 
não faz número comigo. A coletividade em que eu digo 'tu' ou 'nós' não é um plural de 'eu'. Eu, tu, não são indivíduos de um conceito comum. (Lèvinas, 1988: 26)

Outrem, portanto, nos remete à comunidade no sentido deleuziano - instância impessoal e paradoxal que reúne as "diferentes séries" sem pertencer a nenhuma delas: sendo impessoal (nem eu, nem tu), a comunidade a ninguém pertence, mas participa do processo diferenciador e aproximativo; sendo paradoxal, põem fim ao sujeito ao mesmo tempo em que se constitui como fonte de produção do novo. É tal concepção que podemos ler em Espósito quando ele afirma a existência de um "sujeito da comunidade" sendo, necessariamente, o Outro, entretanto, "não um outro sujeito, mas uma cadeia de alteridade que não se fixa nunca numa nova identidade" (Espósito 2007: 18).

É justamente na comunidade onde se dá o processo de vinculação - conforme Sodré (2002: 223), "núcleo teórico da comunicação: a vinculação entre o eu e o outro". Retomando Blanchot (1983: 12), a comunidade não se dá na relação entre aqueles que encerram entre si uma relação do "même avec le même", ou seja, na totalidade homogênea, a exemplo do comunismo (esta seria, segundo ele, a morte da comunidade), mas na diferença do "même", que nos aproxima e nos diferencia uns dos outros ${ }^{14}$.

"Vinculação", como sugere Sodré (2002: 223), "radicalidade da diferenciação e aproximação entre os seres humanos", para Michel Maffesoli trata-se de uma "potência subterrânea" (explosiva) que retorna, ciclicamente, às formações societais de todas as formas humanas gregárias, esgotando em si (na consumação do vínculo) toda sua energia. Enquanto tal, não possui qualquer objetivo além deste: estar junto, estar-com.

Parece-me que a "potência" não deixa nunca de desempenhar um papel. Sua ação, no entanto, é ora secreta, ora discreta, ora notória. Quando não se exprime nessas formas de efervescência que são as revoltas, as festas, os levantes e outros momentos quentes das histórias humanas, ela se hiperconcentra no segredo de seitas e das vanguardas, sejam elas quais forem, e se hipoconcentra nas comunidades, nas redes, em suma, nos fatos menores da vida cotidiana, que são vividos por eles mesmos e não em função de uma finalidade qualquer. (Maffesoli, 2006: 68-69)

\footnotetext{
${ }^{14}$ A influência de Lèvinas é marcante em Blanchot. Provém daí o apelo necessário ao Outro a quem devemos respeito e que nos é indispensável à vida. Nestes autores é evidente a ética (e não a ontologia) como filosofia primeira.
} 
Tais vinculações têm se revelado em certas formações constituídas por relações (ou economia) das dádivas, conforme o princípio da communitas $(c o m+$ munus $)$. Para Espósito, na communitas expressam-se o dever, a dívida, a obrigatoriedade do dom (munus) para "-com" alguém, sendo exatamente isso o que mantêm unidos, e em relação de reciprocidade, os membros de uma associação humana. Munus-com ou com-munus é a abertura, a doação incondicional ao Outro (e à Outrem) que, tal como a experiência da morte, nos expropria enquanto sujeito e nos revela, reiteradamente, não se tratar de uma substância comum, uma propriedade ou um atributo o que constitui a comunidade, mas justamente o seu contrário; “communitas é o conjunto de pessoas que une não uma 'propriedade', mas justamente um dever e uma dívida” (Espósito, 2003: 29).

Para Espósito, a experiência comunitária ou experiência da morte, foi soterrada com o advento da Modernidade. Curioso perceber que foi tal época não apenas aquela que inventou o sujeito enquanto entidade que projeta sobre o mundo sua expressão unitária e soberana (excluindo as diversidades), mas também as instituições inmunizantes voltadas precisamente para o ressarcimento da dívida - sistemas de igualdade e controle social (o Estado e os aparatos legislativo), justiça e equivalência as quais destroem todas as diferenças ${ }^{15}$. No entanto, como inúmeros estudos têm apresentado, as experiências comunitárias resistem ainda em nosso tempo, em seus modos singulares e múltiplos, às vezes integradas em lugares in-munizantes cuja conciliação parece impossível: Mercado ${ }^{16}$. Tal compulsão, como acentua Maffesoli, tem se definido como simples desejo do estar junto, do ser-com.

\footnotetext{
15 A força, organicidade e consistência do vinculo é maior na medida em que este equilíbrio (justiça equitativa) se desfaz. Universalidade, homogeneidade, equivalência, entre outros, compõe as formas sociais buscadas pela modernidade. Autores como Kelen Leite (2007: 27) chegam mesmo a se indagar se a paixão moderna pela igualdade (Tocqueville) não seria, em parte, uma das transposições mais influentes do mercado nos relacionamentos sociais.

${ }^{16}$ Dádiva e mercado, afirmam Jacques Godbout \& Alain Caillé (1999), não são excludentes entre si e as relações sociais existentes não se reduzem às relações de interesses econômicos, embora em nossa sociedade haja o predomínio destes sobre a gratuidade ou a doação. A ação social, por exemplo, não é somente orientada por motivações racionais e a busca por vantagens, pois nela interagem outros elementos como a amizade, a solidariedade, obrigação espontânea, o dom e a dádiva. Para eles, o que fazem as empresas funcionarem (e obterem sucesso) não é apenas a universal e abstrata lei de mercado, mas um sistema interdependente de relações de confiança e vínculos dos mais diferentes tipos, os quais atuam juntos à lei econômica da oferta e da demanda.
} 


\section{Estética comunitária}

Extraviar-se, perder o controle de si, se abre como possibilidade de um "encontro inesperado" - entendendo esta expressão como experiência do com-, estarcom, estar-junto. "Encontro" pressupõe, necessariamente, mais de um (o Outro); "inesperado" é sempre o diferente do mesmo (caso contrário seria esperado, previsível).

Este encontro pode acontecer no próprio indivíduo, desde que como "experiência interior" (Bataille, 1992) de transformação radical, como fora dele, na multidão, nos mais diferentes espaços sociais e nas mais improváveis situações (festas, missas, campeonatos esportivos, etc.). Aqui o coletivo é vivido e celebrado esteticamente $^{17}$, no simples e prazeroso estar-com.

Gianni Vattimo, citando a interpretação de Gadamer sobre o parágrafo 9 da Crítica do Juízo de Kant, argumenta a beleza do "estar-junto" (ser-com) na recepção de um objeto artístico.

[nós poderíamos] identificar a experiência do belo com uma experiência vivida de comunidade, que não é nem idêntica ao prazer de uma descoberta científica ou de uma afinidade moral, mas é um sentir-se "bem" com o nosso próximo na contemplação, ou ainda na apreciação de certos objetos, não enquanto úteis, ou enquanto bons, ou enquanto verdadeiros, e sim justamente enquanto belos. (Vattimo, 2007: 64)

O belo como experiência comunitária, de que fala Vattimo, pode ser entendida como experiência da subtração (des-in-munizar), "encontro inesperado" na contemplação e na multidão. Mesmo no domínio do campo estético-artístico, tal experiência foi obliterada na modernidade em seu processo de inmunização, no que se manifesta na reclusão da arte "social" da antiguidade (templos e teatros) ao domínio privado (a exemplo dos retratistas), desvinculada de qualquer laço ou dívida (do artista para com a sociedade, da sociedade para com o artista), restrita apenas a uma relação de equivalência: compra e venda.

Convém perceber que esta ideia de privatização constitui, ainda hoje, a condição fundamental da apreciação estética (para Theodor Adorno, por exemplo, tais objetos

\footnotetext{
${ }^{17}$ Estética aqui compreendida tal como em Maffesoli (2006: 130), etimologicamente: "faculdade comum de sentir, experimentar".
} 
devem ser fruídos individualmente). Todavia, frente às experiências (recepção) solipsistas da obra de arte, surgem centros agregadores da diferença, os quais colocam em questão a beleza do estar-junto, a exemplo dos espetáculos musicais, salas de cinema (num período de declínio da solipsista televisão), lugares onde não se pode mais ficar alheio.

Como observa Michel Maffesoli, grande parte destas experiências tem sido deixada de lado, consideradas como inúteis, banais e insignificantes, manifestações da alienação humana. Entretanto, em sua cotidianidade as pessoas resistem aos processos homogeneizadores e formas políticas de dominação do comum. Esta seiva de "socialidade" que atravessa os sujeitos e os vincula entre si (centralidade subterrânea) constitui a grande expressão política da contemporaneidade: o retorno da "tribo" é diferencial, não mecânica, guarda em si um elemento vitalista, criativo.

\section{Um caso exemplar}

O romance "Viva o povo brasileiro", do escritor baiano João Ubaldo Ribeiro, é uma obra fantástica que fala sobre a saga de uma certa irmandade do "Povo Brasileiro" frente a uma série de eventos que se estendem desde a invasão holandesa do século XVI às formas populistas e nacionalistas do século XX, atravessando outros acontecimentos como a Independência, a Guerra de Farrapos, a Guerra do Paraguai, a Abolição, a Proclamação da República e a Batalha de Canudos. O título faz alusão à exclamativa voz que acompanha os momentos de fervilhamento popular das multidões (levantes, insurreições, revoluções, etc.), impostada pela voz de um líder. Elegemos esta obra para encerrar este trabalho porque em uma de suas passagens, talvez a mais importante, Ribeiro (1984) consegue descrever (com detalhes que só é possível numa obra de arte) a experiência (estética) comunitária, o estar-junto ou estar-com, desde o seu desenrolar primeiro.

A cena a seguir se passa numa reunião de escravos numa "casa da farinha", propriedade do barão Perilo Ambrósio de Pirapuama.

Nenhum dos outros três já vira um cachimbo como aquele, nem mesmo sabiam direito como se fazia para beber a fumaça do tabaco, embora se falasse muito em gente, tanto brancos como negros, que gostava de beber fumo. Não era coisa que se testemunhasse com 
facilidade, e então ficaram quietos durante todo o tempo que Dandão levou para, depois de assentar a brasa dentro do fornilho e juntar as mãos sobre ela como se fosse tapá-la, sugar repetidamente a ponta da caninha e finalmente cobrir-se de uma fumaça azulada de aroma áspero que lhe saía pelos cantos da boca e pelo nariz, talvez por todos os buracos da cabeça. Como um engenho a vapor, permaneceu solidamente imóvel, soltando fumaça em assopradelas alongadas, volta e meia cuspindo à distância sem mexer a cabeça. Seu rosto agora se descobria um pouco, viam-se os olhos injetados e semicerrados, o pensamento em outro lugar.

Até que finalmente começou a falar, embora não abandonasse de todo o cachimbo, ao qual voltava de quando em vez, atiçando o brasido com chupadas curtas e enérgicas, até rodear-se novamente de nuvens azuis. Estava diferente do habitual e não só pela fumaça, mas pela expressão menos rude, a fala suavizada, o tom de camaradagem. Ainda assim não era um homem comum, igual aos outros, ainda assim continuava misterioso, mas era como se eles pudessem vir a partilhar do mistério, talvez não agora, talvez nunca, irias talvez sim. Primeiro mencionou Nego Lírio, que não viera porque não queria saber daquelas conversas. (Ribeiro, 1984: 207-208)

Neste momento algo irrompe. Uma mudança acontece em meio à fumaça (nebulosa, atmosfera), algo que, junto às palavras de Júlio Dandão, faz surgir um "rosto" (Lèvinas), desencadeando um abrir-se ao Outro, um vincular-se neste momento de ex-stase (sair de si).

Zé Pinto pareceu atemorizar-se com aquilo, mas Dandão virou-se para ele e disse, como se estivesse descrevendo um acontecimento corriqueiro, que efetivamente tinham matado o barão. Não só tinham matado o barão, como matariam muitos mais barões e fariam outras coisas igualmente portentosas. Observassem bem, não se tratava só de vingança, ia bem além disso, muitíssimo além. [...] Budião sentiu-se tonto, acreditou até que era por causa da fumaça do cachimbo. Olhou para os dois companheiros, ambos pareciam tontos também, Zé Pinto sacudindo a cabeça como quem não acredita no que vê e ouve, Feliciano exaltado e irrequieto, reproduzindo a saudação ensinada por Dandão. Budião voltou-se para Dandão, intrigou-se com a tranquilidade com que ele falava aquelas coisas terríveis e difíceis, acabou dizendo que não tinha entendido nada direito

Tu entendeu, Zé Pinto? - perguntou.

- Da-da-da-da - respondeu Zé Pinto, com os olhos baixos.

- Tu vais entender - disse Júlio Dandão. - Eu vou mostrar um segredo. Vou mostrar mais de um segredo, segredos que eu venho guardando sozinho, mas não devo mais guardar sozinho. Antes, todos os que sabiam desses segredos morreram ou desapareceram, só fiquei eu, com essa missão de guarda. Mas segredo de um só não serve para nada, só leva ao desvario do juízo e à perda completa da ideia. De maneira que chegou a hora de dividir esses segredos, que é o único 
jeito de manter esses segredos inteiros. Mas não é somente para mostrar, é também para fazer. (Ribeiro, 1984: 210)

O segredo de que fala Dandão, e em torno do qual se desenvolve toda a saga de "O povo brasileiro", funciona de maneira semelhante à leitura lacaniana da "carta roubada" de Edgar Allan Poe; pois embora seu conteúdo (significado) nunca se revele ou caso se revele é de maneira enviesada, por vezes enigmática -, este não parece ser tão importante quanto a própria carta (significante) na organização de toda a trama narrativa. Lembremos que o segredo, como observa a sociologia formal de Georg Simmel (1939), é o que permite a constituição de grupos, a diferenciação e aproximação dos indivíduos entre si tanto na sociedade quanto no interior destes mesmos grupos (as chamadas panelinhas) ${ }^{18}$. Aqui, o segredo sugere uma ameaça silenciosa daqueles que o detêm (tal como a possibilidade de uma conspiração ou um complô), um tipo de poder na submissão que o hegemônico ou o instituído teme e contra o qual nada pode fazer.

- Estes segredos - disse sem tirar a mão da tampa - são parte de um grande conhecimento, conhecimento este que ainda não está completo, mesmo porque nenhum conhecimento fica completo nunca, faz parte dele que sempre se queira que ele fique completo. E faz parte dele também, por ser segredo e somente para certas pessoas, que cada um que saiba dele trabalhe para que ele fique completo. Se todos trabalharem, geração por geração, este é o conhecimento que vai vencer.

Budião, Feliciano e Zé Pinto continuaram sem compreender direito o que ele estava dizendo, mas não sentiram vontade de perguntar nada, como se tivessem certeza de que acabariam compreendendo. Mesmo porque, enquanto falava entre seus rolos de fumaça, Dandão ficou muito maior, muitíssimo maior, mais alto do que a casa que o continha, ficou de todas as cores e expressões, ficou até transparente, ficou úmido como o entrepernas de uma mulher e sabido como a raiz da árvore, ficou uma verdadeira paisagem. E então soltou de vez a tampa, que voltou a escancarar-se pendulando até achar sua posição, e de lá principiou a puxar segredos, um segredo atrás do outro, cada qual mais maioral, havendo quem afirme terem sido libertados inúmeros espíritos de coisas, maneiras de ser, sopros trabalhadores, papéis que não se podia ver com os dois olhos para não cegar, influências aéreas, as verdades por trás do que se ouve, sugestões inarredáveis, realidades tão claras quanto o imperativo de viver e criar filhos. Foi também tudo muito sonoroso, tão melódico que nada mais se escutou dentro da casa da farinha, dizendo uns que ali, naquela hora, se fundou uma irmandade clandestina, a qual irmandade ficou sendo a do Povo Brasileiro, outros dizendo que não houve nada, nunca

\footnotetext{
${ }^{18}$ O conteúdo da sociação (neste caso, o segredo) não é tão importante para Simmel quanto a forma. Esta, segundo o autor constitui o objeto "puro" de sua sociologia.
} 
houve nada, nunca houve nem essa casa dessa farinha desse engenho desse barão dessa armação, tudo se afigurando mais labiríntico a cada perquirição. Enquanto Júlio Dandão vai aos poucos catando na canastra o que mostrar e vai exibindo alguma coisa e explicando outra, essa Irmandade talvez esteja se fundando, talvez não esteja, talvez tenha sido fundada para sempre e para sempre persista, talvez seja tudo mentira, talvez seja a verdade mais patente e por isso mesmo invisível, porém não se sabendo, porque essa Irmandade, se bem que mate e morra, não fala. (Ribeiro, 1984: 212).

A narrativa descreve aquilo que caracterizamos ao longo deste trabalho como sendo o comum da comunidade (perda, dessubstancialização, dessubjetivação assujeitamento...), sendo sua natureza impessoal, paradoxal, atmosférica, silenciosa, misteriosa, disforme, fantasmagórica, porém vinculante: em seu aspecto atmosférico, a irmandade vincula os escravos num vazio comum e os dilacera. A comunidade, como frisamos, não pertence a ninguém, embora haja sempre aqueles (lideres carismáticos, políticos, cientistas, filósofos, etc.) que desejam expropriar a substância onde a comunidade, por um breve instante, se projeta. Não obstante, frente à comunidade, muitos preferem permanecer em sua individualidade (in-munizados) - lembremos que, antes do encontro na casa da farinha, um dos escravos diz a Budião não querer participar, certamente por estar ciente do risco que isso implica (sua morte enquanto sujeito): “[...] ele disse que sabe muito bem que conversa é essa” (Ribeiro, 1984: 206). Outros, incluindo o próprio narrador, se entregam irrevogavelmente ao evento e, como se estivesse lá, recupera em detalhes, a experiência comunitária.

\section{Conclusão}

A concepção de comunidade desenvolvida por pensadores como Bataille, Nancy, Agamben e Blanchot nos lança em um lugar diferente daquele a que estamos habituados quando nos referimos à comunidade. Ao invés de um compartilhamento de substância comum (território, língua, cultura etc.), justamente o seu oposto: o nada-emcomum. A comunidade apresenta-se, neste caso, como relação, descontinuidade que rompe a cadeia de fechamento (in-munus) ou de individualização, expelindo o indivíduo para fora, para a relação. O sujeito, enquanto instância de controle da subjetividade, quando submetido à experiência comunitária, sucumbe diante da comunidade; ele vê esvair-se sua subjetividade e interioridade por um traço (com-) que o arranca de si. 
Neste paradoxal jogo da comunidade, a morte do sujeito inaugura também a possibilidade do novo, de uma existência singularmente criativa.

\section{Referências bibliográficas}

AGAMBEN, Giorgio. A comunidade que vem. Lisboa: Presença, 1993.

ANTOUN, Henrique; MALINI, Fábio. Ontologia da liberdade na rede: as multi-mídias e os dilemas da narrativa coletiva dos acontecimentos. XIX ENCONTRO DA COMPÓS, 2010, Rio de Janeiro. Anais do XIX Encontro da Compós, Rio de Janeiro, 2010.

BATAILLE, Georges. A experiência interior. São Paulo: Ática, 1992.

BLANCHOT, Maurice. La communauté inavouable. Paris: Minuit, 1983.

DELEUZE, Gilles. A lógica do sentido. São Paulo: Perspectivas, 2007.

ESPÓSITO, Roberto. Communitas: origen y destino de la comunidad. Buenos Aires: Amorrortu, 2003.

Niilismo e comunidade. In: PAIVA, Raquel (org.) O retorno da comunidade: os novos caminhos do social. Rio de Janeiro: Mauad X, 2007: 15-30.

GOUDBOUT, Jacques; CAILLÉ, Alain. O espírito da dádiva. Rio de Janeiro: FGV, 1999.

LEITE, Kelen C. As Possíveis contribuições do M.A.U.S.S. (Movimento Anti-Utilitarista nas Ciências Sociais) para repensar as relações entre Estado, Mercado e Sociedade Civil. InterAÇÕEES - Comunidade e Cultura. Uberlândia, v. 02, n. 02, 2007: 13-34.

LÈVINAS, Emmanuel. Totalidade e infinito. Lisboa: Edições 70, 1988.

MENDES, João. No espaço Llansol (conversa a propósito de Lisboaleipzig). Lisboa: Público/ Leituras, 1995.

MAFFESOLI, Michel. O tempo das tribos: o declínio do individualismo nas sociedades de massa, Rio de Janeiro: Forense Universitária, 2006.

NANCY, Jean-Luc. La communauté désoeuvrée. Paris: Christian Bourgois Editeurs, 1986.

. La communauté affrontée. Paris: Éditions Galilée, 2001.

NISBET, Robert. La tradicion sociologique. Paris: Quadrige/PUF, 1993.

PALÁCIOS, Marcos. Sete teses equivocadas sobre comunidade e comunicação comunitária. Revista Comunicação e Política, v. 9, n. 11, Salvador: FACOM-UFBA, 1990: 103-110.

PELBART, Peter Pál. Vida capital: ensaios de biopolítica. São Paulo: Iluminuras, 2003.

RIBEIRO, João Ubaldo. Viva o povo brasileiro. Rio de Janeiro: Nova Fronteira, 1984. 
SIMMEL, Georg. El secreto y la sociedad secreta In: Sociología: estudios sobre las formas de socialización. Buenos Aires: Espasa-Calpe Argentina S.A., 1939: 330-392.

SODRÉ, Muniz. Sobre a epistème comunicacional. Revista Matrizes. v. 01, n. 01, 2007: 1526.

Antropológica do espelho: uma teoria da comunicação linear e em rede. Petrópolis: Vozes, 2002.

TARIZZO, Davide. Filósofos em comunidade. Nancy, Espósito e Agamben. In. PAIVA, Raquel (org.) O retorno da comunidade: os novos caminhos do social. Rio de Janeiro: Mauad X, 2007: 31-62.

VATTIMO, Gianni. O belo como experiência comunitária. In. PAIVA, Raquel (org.). O retorno da comunidade: os novos caminhos do social. Rio de Janeiro: Mauad X, 2007: 63-68.

YAMAMOTO, Eduardo Y. O discurso comunitário: comunidade, sociedade e comunicação. In: MORAES, Osvando J (org.) Tendências atuais da pesquisa em Comunicação no Brasil. São Paulo: Intercom, 2008: 315 - 336 . 